\title{
Pátzcuaro \\ DA LA BIENVENIDA AL TURISTA. LA OBRA DE LÁZARO CÁ́RDENAS AL NORTE DE LA CIUDAD
}

Pátzcuaro welcomes the tourist. Lazaro Cardenas's work north of the city

$$
\text { José Manuel Martínez-Agullar*, Catherine R. Ettinger-McEnulty** }
$$

Fecha de recibido:

22 Noviembre 2020

\author{
*Universidad Michoacana de San Nicolás de Hidalgo, \\ México. \\ majmanuel999@hotmail.com \\ **Universidad Michoacana de San Nicolás de Hidalgo, \\ México.
}

catherine.ettinger@umich.mx
RESUMEN. En la década de 1930 el presidente de México, Lázaro Cárdenas, ordenó una serie de obras de mejoramiento urbano, infraestructura y equipamiento turístico al norte de la ciudad de Pátzcuaro, con el fin de crear una entrada pintoresca para turistas en el principal acceso carretero y en los alrededores de la estación ferroviaria. Dichas obras dieron una transformación del paisaje y la creación de escenarios pueblerinos para satisfacer la imaginación del visitante. A partir de la revisión pormenorizada de los cambios efectuados en la zona norte de Pátzcuaro, que daba la bienvenida a los visitantes que llegaban en automóvil o en tren, se revela la importancia dada no sólo al embellecimiento, sino también a la creación de un escenario rural o campestre que, para el final de mandato presidencial de Cárdenas, en 1940, se habían concretado claramente.

Palabras clave: arquitectura campestre, cardenismo, escenarios pueblerinos, turismo.
ABSTRACT. During the 1930 s the president of Mexico, Lazaro Cardenas, ordered a series of urban works as well as the creation of tourist infrastructure in the city of Patzcuaro in order to create a picturesque entrance to the city for tourists arriving by car or by train. These works implied a radical transformation of the landscape and the creation of rural settings to satisfy the visitor's imagination. Through a detailed review of the changes made in the northern area of Pátzcuaro, which welcomed visitors who arrived by car or train, the authors illustrate the importance given not only to beautification, but also to the creation of a rural setting that was consolidated by the end of Cárdenas's presidential term in 1940.

Key words: country architecture, cardenismo, village settings, tourism. 


\section{Itsing QUEDA PATENTE EN EL ESTABLECIMIENTO DE LA COMISIÓN PROTURISMO EN 1928 \\ Y DE LA COMISIÓN NACIONAL DE TURISMOEN 1934.}

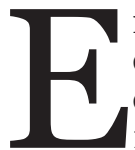
n México, el turismo constituyó una cuarta, y menos visible, prioridad de la Revolución Mexicana (19101921), después de la educación, salud y vivienda. El estado trabajó desde los años veinte en forjar una nueva imagen del país en el extranjero -retratado por viajeros del siglo XIX como lugar de bandidos y aventureros- como sitio de cultura y de milenarias tradiciones (Delpar, 1992). En 1921 se estableció la Escuela de Verano de la entonces Universidad Nacional de México con la participación de destacados intelectuales mexicanos para promover a través de esta institución el conocimiento de la cultura mexicana entre extranjeros (Sánchez, 2013). La importancia del turismo queda patente en el establecimiento de la Comisión ProTurismo en 1928 y de la Comisión Nacional de Turismo en 1934. Tan relevante era el tema que, en 1934, en el discurso inaugural de su presidencia, Lázaro Cárdenas lo anunció como política fundamental de su sexenio. Un mes después quedó claro - con el cierre de los afamados hoteles Aguacaliente en Tijuana y Casino de la Selva en Cuernavaca- que no sólo sería prioridad el fomento al turismo, sino también cambiaría su orientación: México ya no sería lugar de bebida, prostitución y juegos de azar (Merril, 2009: 89), más bien su imagen se renovaría en el extranjero como sitio de tradiciones y de poblados pintorescos.
Los esfuerzos del presidente Cárdenas se concentraron en la construcción de la infraestructura turística -carreteras, hoteles y estaciones de servicio-. La apertura del primer tramo de la carretera panamericana en 1936, que conectaba a Laredo con la Ciudad de México, implicó no sólo un impulso al turismo internacional en automóvil, sino que significó una radical transformación del paisaje y del territorio nacional. Con ramales a Acapulco y a Guadalajara, y con la ruta adicional de Nogales a Guadalajara, se abrió un vasto territorio al turismo nacional; el trazo de la carretera -atentó a la cuestión de las vistasno sólo reveló un paisaje desconocido, sino que, en cierto sentido lo creó (Jackson, 2011). Y en la época del auge del motorismo, aparece una y otra vez en guías de turismo como uno de los grandes atractivos de un viaje a México (Power, 1940).

Otro aspecto recurrente en la literatura sobre el turismo de automóvil era la percepción de libertad, que daba a los viajeros de explorar el territorio sin atenerse a los horarios y las rutas fijas de las vías férreas; podían entrar a los poblados rurales, inclusive fuera de la carretera principal, y experimentar lo que consideraban el "verdadero México".

1 Dicho tema es recurrente en las guías de turismo (ver Berlin Goolsby (ca. 1938: 44). 
En la intersección entre los estudios de turismo $y$

\section{LA HISTORIA DE LA ARQUITECTURA SE HAN REALIZADO TRABAJOS SOBRE LOS HOTELES Y OTROS EDIFICIOS PARA EL HOSPEDAJE, SOBRE LOS RESTAURANTES DE LAS CARRETERAS Y TAMBIEN SOBRE LAS GASOLINERASO ESTACIONES DE SERVIIIO.}

Sin duda, con conciencia de este anhelo del turista, México comenzó a promover destinos pueblerinos y, en el marco de esa promoción, a crear escenarios propicios para la imaginación del turista. En ese contexto se sitúa el desarrollo de diversos sitios del turismo -Taxco, Guerrero, Cuernavaca, Morelos y Pátzcuaro, entre otros- que en los años treinta implementaron legislación para atender la imagen urbana y recibieron apoyos para la dotación de servicios turísticos -hoteles y estaciones de servicioy de equipamiento cultural. Pátzcuaro, como lo ha señalado Jolly (2018), fue un sitio paradigmático de las políticas cardenistas en el tema, debido a sus bellezas naturales, arquitectura y cultura; por ser el punto de salida hacia Janitzio y la ribera del lago, y por estar en el punto intermedio entre Morelia y Uruapan. Por algunas de estas razones, el mismo Cárdenas, el general Francisco J. Múgica, el ingeniero Efraín Buenrostro y otros personajes de la vida política del país eligieron este lugar para construir sus quintas.

Este trabajo, que versa sobre Pátzcuaro, se apoya en diversas investigaciones que establecen la importancia de las actuaciones de Cárdenas a finales de la década de 1930 y principios de 1940 a través de la creación de equipamientos culturales como el Teatro Emperador Caltzontzin, la Biblioteca Pública Gertrudis Bocanegra y el Museo de Artes y Oficios, de equipamientos turísticos como la monumental estatua de Morelos en la isla de Janitzio, el mirador Balcón Tariácuri y el mirador Cerro Colorado -el Estribo Chico- (Ettinger, 2020a: 67-83; Martínez, 2019: 1079-1109; Jolly, 2018), y de un programa artístico de pintura mural y escultura de héroes en diversos puntos de la ciudad. ${ }^{2}$ Hay trabajos puntuales sobre algunos de los participantes en las obras de la región, como Juan O'Gorman (Rodríguez, 1982), Alberto Le Duc (Ettinger, 2020b), Guillermo Ruiz (Arteaga, 2010) y Roberto Cueva del Río (Ettinger, 2018a: 137-162), y textos que rescatan la memoria local sobre el periodo. En la intersección entre los estudios de turismo y la historia de la arquitectura se han realizado trabajos sobre los hoteles y otros edificios para el hospedaje, sobre los restaurantes de las carreteras, las gasolineras y estaciones de servicios. Estos elementos aparecieron de manera visible en las principales rutas en los años 30, 40 y 50, con tipologías propias, pero el turismo de principios del siglo $\mathrm{xx}$, especialmente de automóvil, no sólo generó nuevos edificios como hoteles, estaciones y gasolineras, sino implicó adecuaciones y mejoras urbanas, sobre todo en las entradas a los poblados. Para el caso de México, donde uno de los productos que se ofrecía a los turistas eran los poblados pintorescos, estos arreglos fueron de gran importancia.

El presente trabajo complementa dicha bibliografía, revisando las obras urbanas ordenadas por Cárdenas en Pátzcuaro, que pretendían embellecer la entrada a la ciudad. Para ello se emplea el método de la historia que, a partir del análisis testimonios diversos -en este caso correspondencia inédita y fotografía histórica- construye una narrativa. Se ubica en el campo de la investigación humanística $\mathrm{y}$, siguiendo a Collingwood (1994), en lugar de comprobar hipótesis, describe, analiza y evalúa para llegar a la interpretación. La intención en este trabajo es ir más allá de aspectos generales tratados por otros autores o de la revisión puntual de la arquitectura para el turismo para indagar la manera en que se articuló el poblado histórico de Pátzcuaro con el nuevo ramal de la carretera Ciudad de México-Guadalajara. A partir de la revisión pormenorizada de los cambios efectuados en la zona que daba la bienvenida a los visitantes que llegaban en automóvil o en tren, se revela la importancia dada no sólo al embellecimiento, sino también a la creación de un escenario rural o campestre. También, a través de documentación inédita, se muestra la cercana participación del general Lázaro Cárdenas, en los proyectos implementados.

2 Dicho tema es recurrente en las guías de turismo (ver Berlin Goolsby (ca. 1938: 44). 


\section{UN NUEVO ACCESO PARA LA CIUDAD}

La vocación de Pátzcuaro de recibir a visitantes data del periodo colonial, en donde por su ubicación fungió como punto de llegada de arrieros que viajaban entre la Tierra Caliente al sur de Michoacán y el centro del país.

Todavía hasta mediados de la década de 1930 la entrada principal de Pátzcuaro para quienes venían del centro del país, de Morelia o de los poblados que se ubicaban al oriente de la ciudad era por el antiguo Camino Real o Calle Nacional -actual avenida Benigno Serrato-. Sobre este acceso se encuentra la capilla El Humilladero, que tiene sus orígenes en una cruz de caminos que marcaba la entrada a la ciudad en el siglo XvI, lo que sugiere antecedentes prehispánicos de esta arteria. Este acceso histórico pasó a segundo término de manera más clara con la construcción del ramal, que conecta a Pátzcuaro con la carretera nacional Ciudad de México-Guadalajara, que estableció el norte de la ciudad como la entrada principal a la ciudad para motoristas, ya fueran turistas o residentes, que venían de Morelia, la capital del estado o del centro de país. ${ }^{3}$ El cambio impulsó un crecimiento hacia el norte, que había comenzado desde finales de los años veinte a través de la creación de tres colonias en tierras que habían formado parte de la hacienda de Ibarra: la colonia Ibarra, la Revolución y la Morelos. ${ }^{4}$ Otra vía importante fue promovida por Cárdenas con el apoyo de Francisco J. Múgica entre 1939 y 1940 para conectar el norte de Pátzcuaro con poblados ribereños; ese camino, Circunvalación, ahora libramiento Ignacio Zaragoza, facilitaría acceso a las comunidades indígenas para turistas que viajaban en auto (Sosenski, 1999: 28).

La modernización de esta parte de la ciudad no estaba completa sin la renovación y embellecimiento de las proximidades de la Estación del Ferrocarril y las avenidas que llevaban al muelle principal y a un nuevo muelle construido en la colonia Morelos, conocido ahora como Las Garzas. El nuevo acceso carretero y la presencia de la estación de ferrocarril requirieron de la creación de equipamientos turísticos en la zona, incluyendo obras públicas como el nuevo

\footnotetext{
3 Obras importantes en la carretera México-Guadalajara (1939, 25 de enero). El Informador, p. 4.

4 La colonia Morelos se fundó después de 1932, donde se levantaron quintas campestres neocoloniales para varios ex militares y colaboradores cercanos del general Cárdenas como Efraín Buenrostro, Martín del Campo y Carlos Moya (Martínez, 2016: 141-142; García Sánchez, 2017).
}

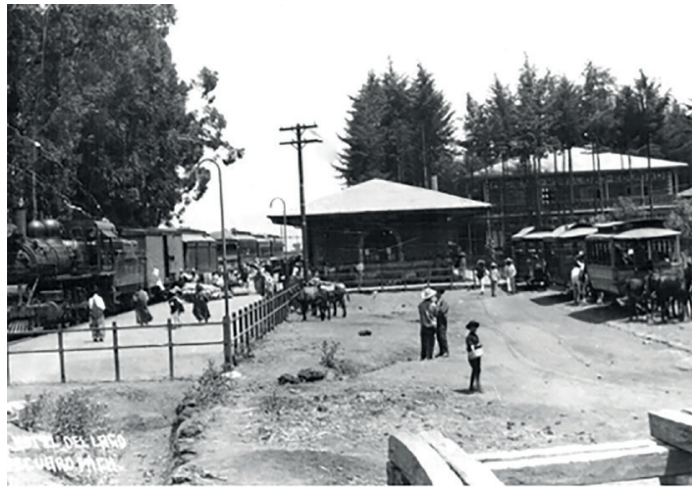

FIGURA 1. ESTACIÓN DEL FERROCARRIL DE PÁTZCUARO Y HOTEL DEL LAGO. CA. 1934 FUENTE: FOTOTECA DEL ARCHIVO HISTÓRICO MUNIIIPAL DE PÁTZCUARO

muelle y el mirador de Cerro Colorado, y privados, como hoteles, restaurantes y una estación de servicios para automóviles. En la figura 1, tomada alrededor de 1934, se observa la estación del ferrocarril vista de suroeste a noreste; a la derecha se aprecia el tranvía y atrás el Hotel del Lago.

\section{LOS EQUIPAMIENTOS TURÍSTICOS Y URBANOS}

La transformación de Pátzcuaro, durante el sexenio de Lázaro Cárdenas como presidente (1934-1940), ha sido abordada en diversos textos (Jolly, 2018; Martínez, 2019: 10791092; Ettinger, 2020a: 67-83). Destaca la introducción de nuevos equipamientos culturales y turísticos, así como la creación de monumentos y la realización de obras pictóricas. En el primer rubro se dio la creación de los principales equipamientos culturales de la ciudad -el teatro Emperador Caltzontzin, ${ }^{5}$ la Biblioteca Gertrudis Bocanegra y el Museo de Artes e Industrias Populares- que atenderían a la población local y visitante a la región. En relación con el turismo, el periodo vio la apertura del hotel Posada de don Vasco, 1939, ${ }^{6}$ que venía a complementar los mesones, hoteles del centro y los alojamientos cerca de la estación. ${ }^{7}$ Como parte de la infraestructura turística se encontraban también los miradores Cerro Colorado y Balcón de Tariácuri, ${ }^{8}$ así como la gasolinera de Servicios

5 Teatro Emperador Caltzontzin (1938, 1 de julio). Vida, p. 3. 6 Según la placa en su acceso, fue construido por la Azteca Compañía Mexicana de Seguros S. A. desde 1938, abriéndose al público en enero de 1939.

7 En la plaza Gertrudis Bocanegra se hallaba el hotel de la Concordia, el hotel Guizar y el hotel Mercado; en las cercanías de la estación de tren se ubicaba el Hotel del Lago y el Hotel Ibarra.

8 El mirador Cerro Colorado o Estribo Chico fue diseñadoy construido por el arquitecto Antonio Llamosa y por el ingeniero Roberto Mejía Ortiz. En este lugar Roberto Cueva del Río realizó dos pinturas murales con el tema "El Tianguis"y "La Danza del Pescado" (Ettinger, 2018: 137-172). El camino empedrado al Balcón Tariácuri fue extendido hasta la cima del cerro del Estribo. 
Espinosa,1940, propiedad del ingeniero forestal Joaquín Espinosa Robleda, amigo cercano de Cárdenas (Cárdenas, 2016: 27). Esta fue la primera estación de servicio de combustible y servicios básicos para los automóviles, construida ex profeso para tales fines (Ettinger, 2018b: 28-50). Su estilo "regional" o neocolonial denotaba el interés de los prestadores de servicios de mostrar al turista una arquitectura moderna, pero propia de México. Su interior fue decorado con una pintura mural del lago de Pátzcuaro, lo que fortalece la idea de que no era solamente una construcción utilitaria, sino que tenía fines estéticos.

La ciudad recibió nuevos momentos y obras relevantes de pintura mural en el mismo periodo. Roberto Cueva del Río, Ramón Alva de la Canal y Ricardo Bárcenas, participaron en obra mural en diversos edificios públicos y escuelas en la región lacustre, mientras que los escultores Juan Tirado y Guillermo Ruiz recibieron comisiones para diversas obras. Ambos participaron en el diseño y construcción de la estatua de Morelos en Janitzio entre 1931 y 1934. Juan Tirado creó el monumento a la Revolución en la colonia del mismo nombre en 1936 y otras obras para la Quinta Eréndira. En 1937 Cárdenas le encargó a Ruiz la elaboración de un monumento a la heroína de la independencia doña Gertrudis Bocanegra y uno a Tangaxoán II, ambas para la ciudad de Pátzcuaro, que fueron terminadas en 1938 y colocadas en dos espacios públicos. La primera escultura se erigió al centro de la plazuela Gertrudis Bocanegra y la de Tangaxoán fue colocada en una glorieta sobre el nuevo acceso a la ciudad. ${ }^{9}$ En 1935, el mismo Cárdenas mandó sustituir un quisco porfiriano que se ubicaba al centro de la plaza principal por una fuente conocida como Pila de los Pescados, diseñada por el patzcuarense Salvador Solchaga, construida por el ingeniero Jesús Martínez y supervisada por el arquitecto Alberto Le Duc.

La visión de Cárdenas era conservar el aspecto tradicional de Pátzcuaro, pero sin impedir la inserción de equipamiento, infraestructura y obras artísticas que favorecieran el desarrollo de la ciudad y la embellecieran. En 1940, al final de mandato presidencial de Lázaro Cárdenas, se había logrado la visión del general de presentar a

9 El encargado de la glorieta y de la base para la escultura de Tangaxoán fue el arquitecto Alberto Le Duc, mismo que se había encargado de la construcción del teatro Emperador, de la remodelación de la Quinta Eréndira y de otros trabajos en la región. Carta del arquitecto Alberto Le Duc al presidente (1936, 17 de enero). Archivo General de la Nación México, Fondo Presidentes, Sección Lázaro Cárdenas del Río (En adelante AGNM-LCR) 568/9, f. 1.
Pátzcuaro como un pueblo típico, pero con las comodidades que el turista exigía. Su interés y apoyo para establecer mecanismos que permitieran la conservación de la arquitectura y los paisajes naturales, así como para introducir la infraestructura turística y embellecer la ciudad se habían concretado claramente.

\section{LAS MEJORAS EN EL NORTE DE LA CIUDAD}

Con la consolidación de la vocación turística en el norte de la ciudad como resultado de la presencia de la estación de tren y la apertura del ramal de la carretera panamericana, así como el auge del automovilismo, la atención se vertió sobre la zona. La llegada a Pátzcuaro, por tren o por automóvil, estaba acompañada de vistas del lago -incluyendo a Janitzio con la estatua monumental de Morelos- y de la zona de los chalets de la playa. En el proyecto cardenista era de suma importancia la promoción de poblados michoacanos en el marco de una idealización de la vida campestre, que en arquitectura dio lugar al desarrollo de la idea de la arquitectura típica (García, 2013; García, 2015: 477-489). Es en este sentido que se emprendieron obras tendientes a crear un acceso que comunicara este ideal.

Una de las actuaciones más interesantes, y tal vez menos notoria, fue la mejora en calles y parques de esta zona, que se hizo acorde al proyecto de crear una imagen pueblerina con fines turísticos y a la imagen campestre que se quería tener en la colonia Morelos. Así, sería importante que, en lugar de utilizar materiales modernos, la pavimentación se realizara con empedrado; así mismo, se dio prioridad a la dotación de áreas verdes en la zona, con fuentes, bancas y faroles. Es de recordarse que se trata de la zona inmediata a la casa de Cárdenas -desde donde se podía tener una panorámica de dichas obras, del lago Janitzio y su obra de Morelos- y que las obras fueron encargadas directamente desde la presidencia.

Se desconoce el motivo por lo que el presidente Cárdenas recurrió en 1936 a la Compañía de Ferrocarriles para la realización de las obras de urbanización. Se puede intuir una falta de recursos en el municipio y una justificación con base en el hecho de que se trataba de obras de infraestructura y embellecimiento de las áreas verdes y avenidas que rodeaban la Estación del tren, frente a la Quinta Eréndira, así como la construcción de un nuevo muelle.

Otro camino se tendió de sur a norte, por todo el borde oriente de la colonia Morelos y siguiendo la dirección del río que 
desembocaba en el lago; este camino que llevaba a un segundo muelle fue conocido como avenida Purépechas -luego Francisco I. Madero, actual avenida de Las Garzas-. Un camino paralelo a las vías del tren, al parecer tenía el nombre de avenida Tzurumútaro, ya que siguiéndolo hacia el oriente conducía al pueblo con ese nombre - ahora se llama calle Héroes de Nacozari-. El edificio principal de la Estación estaba rodeado de predios baldíos que serían convertidos en áreas verdes. Al nororiente del mismo se ubicaría el Parque Central, atrás del mismo edificio estaría el Parque Janitzio y enfrente, cruzando la vía, se encontrarían los dos parques de la avenida Eréndira -ahora llamadas Plazuelas Gemelas de la Estación (figura 2).

Los trabajos encargados por Cárdenas estuvieron a cargo del ingeniero Antonio Madrazo, presidente ejecutivo de los Ferrocarriles Nacionales de México, quien continuamente informaba al presidente sobre los avances de los mismos. En una carta del 27 de julio de 1936 envió al primer mandatario de la República, a través de su secretario Luis I. Rodríguez, una relación de los trabajos que se estaban realizando en las cercanías de la Estación del Ferrocarril; y el 18 de agosto de 1936 mandó un álbum de fotografías de las obras que estaba efectuando en Pátzcuaro, Uruapan y Morelia. ${ }^{10}$

Según los mismos informes del ingeniero Madrazo $^{11}$, elaborados por el ingeniero en jefe Felipe J. Sánchez, con fecha de 20 de julio de 1936, los trabajos incluían la conformación de las avenidas Eréndira, Purépecha y Tzurumútaro con algunos rellenos, la instalación de empedrados en calzadas y banquetas, y las guarniciones correspondientes y canales de desagüe. En conjunto estas avenidas crean conexiones entre la carretera, la estación y los dos muelles. Se instalaron luminarias con faroles de herrería en columnas de cantería en las tres avenidas y el andén de la estación.

Adicionalmente se crearon una serie de áreas verdes que ayudarían al aspecto campestre en la entrada a la ciudad: el parque Central, el parque Janitzio y camellones para las avenidas Eréndira y Tzurumútaro (figura 3). Estas obras en conjunto crean una zona verde para fortalecer una imagen campestre en torno a los caminos. Para su creación

10 Carta del ingeniero Antonio Madrazo a Luis I. Rodríguez (1936, 18 de agosto). AGNM-LCR 514.63/9, f. 13. No se encontró el álbum mencionado en el expediente correspondiente. 11 Carta del ingeniero Antonio Madrazo a Luis I. Rodríguez (1936, 27 de julio). AGNM-LCR 514.63/9, f. 16. Felipe J. Sánchez, Memorandum de las obras en Pátzcuaro, AGNM-LR-33/31225-196 (1936, 20 de julio), fs. 17-19.

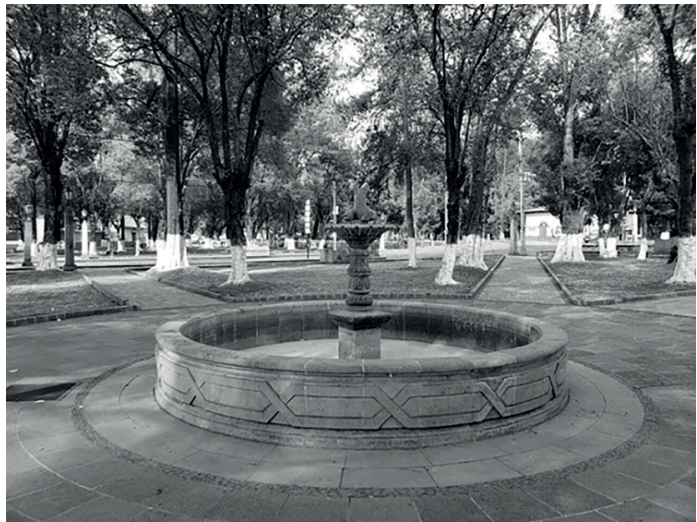

FIGURA 2. VISTA DE UNA DE LAS PLAZUELAS GEMELAS

FUENTE: FOTOGRAFíA DE J. MANUEL MARTÍNEZ, SEPTIEMBRE DE २०२०.

requirieron de rellenos, la creación de cunetas y el acondicionamiento con la instalación de fuentes y bancas.

El muelle principal se terminó desde finales de 1935, pues junto a una carta del ingeniero Madrazo, con fecha del 2 de enero de 1936, le enviaba un par de fotografías al presidente e informaba su conclusión, agregando que con esa mejora se daría facilidades al desembarque de turistas y "a los aborígenes de dicho lago". ${ }^{12}$ El muelle de Las Garzas únicamente se renovó. Desde este lugar un grupo de soldados había transportado en lanchas y canoas, entre 1931 y 1934, los materiales para la construcción del monumento a José María Morelos y Pavón en Janitzio. ${ }^{13}$

En 1935, el presidente municipal, José Ramos Chávez, dijo que el ingeniero Jesús Martínez se hallaba construyendo la carretera que iba desde "la Hacienda Ibarra hasta llegar al crucero de ferrocarril, en contacto con el embarcadero del pueblo de Ihuatzio”. Quizás se refiera a la Avenida de Los Purépechas que llegaba al muelle 2. En esta misiva pide ayuda al ingeniero Martínez para "la obra de reconstrucción de la fuente monumental que adornaba antiguamente la Plaza Principal": la pila de Los Pescados, arriba referida. ${ }^{14}$

12 Carta del ingeniero Antonio Madrazo a Luis I. Rodríguez (1936, 25 de mayo). AGNM-LCR 514.63/9, f. 29. En su libro de Pátzcuaro, Justino Fernández (1936) dijo que "recientemente ha sido construido por orden del señor Gral. Lázaro Cárdenas, un muelle o embarcadero a orillas del lago y cercano a la estación de ferrocarril, por medio del cual se pueden abordar cómodamente las embarcaciones”. Carta del ingeniero Antonio Madrazo a Luis I. Rodríguez (1936, 25 de mayo de 1936). AGNM-LCR 514.63/9, f. 29.

13 Desde su gubernatura Cárdenas comprometió a los militares a participar en diversos proyectos de mejoras sociales y en importantes tareas de infraestructura, dando al ejército el papel de defensor de uno de los ideales de la Revolución (Ginzberg y Nowodworski, 1999: 586).

14 José Ramos Chávez al presidente de la República, AGNMLCR 568/9 (1935, 17 de enero), f. 1. 


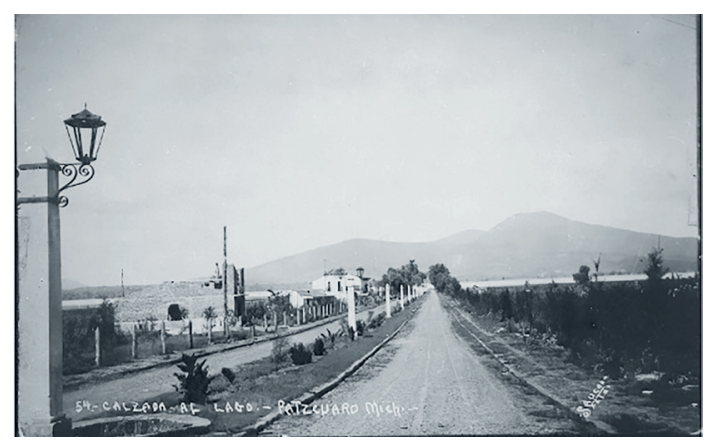

FIGURA 3. VISTA DE LA AVENIDA ERÉNDIRA O CALZADA AL LAGO. SAUCEDO, CA. 1935 FUENTE: FOTOTECA DEL ARCHIVO HISTÓRICO MUNICIPAL DE PÁTZCUARO.

La cercanía con Morelia le permitía a Pátzcuaro atraer a los turistas que llegaban a la capital michoacana, tanto que algunos hoteles ofrecían excursiones guiadas a esta ciudad. En una carta dirigida al secretario del presidente, el licenciado Luis I. Rodríguez, Madrazo le recordaba que el presidente tenía "grande interés por el mejoramiento de Pátzcuaro", que los trabajos que se realizaban al norte de la ciudad estaban casi terminados y que con motivo de la feria que se aproximaba en Morelia confiaba en que Pátzcuaro sería "motivo de grande atracción". Junto a la misiva le hizo llegar al general unas fotografías de las obras terminadas, donde se ve uno de los muelles que se renovó y unas bancas. ${ }^{15}$

En palabras del ingeniero Antonio Madrazo, el presidente Cárdenas no sólo le pidió encargarse de las obras de los alrededores de la Estación del Ferrocarril de Pátzcuaro, sino que les dio indicaciones específicas de cómo debía ser el aspecto que se buscaba, con el fin de ser atractivas para el turismo. Otra carta remitida por Madrazo al secretario del presidente dice que: "[...] los trabajos en la orilla del lago de Pátzcuaro están muy adelantados. He dado instrucciones para que se violente la instalación de faroles coloniales, como lo desea el señor Presidente [...] Las calzadas empedradas están casi terminadas [...] luciendo su aspecto como fueron los deseos del señor General Cárdenas [...] Espero que cuando él de una vuelta por acá quede complacido de los esfuerzos que están haciendo los Ferrocarriles en este centro que será un lugar de atractivo para el turismo [...] Hoy salgo para Uruapan, donde también están casi terminados los trabajos del parque que él me recomendó”. En la misma carta hace notar que existía una falta de fuerza para producir buen voltaje en los arbotantes, pero que el señor Lazcano -Luis Ortiz Lazcano, propietario de la empresa de Luz Eléctrica-, trabajaría una maquinaria que ha encargado para producir ese aumento de voltaje. ${ }^{16}$

15 Carta del ingeniero Antonio Madrazo a Luis I. Rodríguez (1936, 6 de abril). AGNM-LCR 514.63/9, fs. 24-25.

16 Carta del ingeniero Antonio Madrazo a Luis I. Rodríguez.

\section{CONCLUSIONES}

Durante los trabajos realizados al norte de la ciudad, la relación que tuvo el presidente de la República con los diferentes ediles de Pátzcuaro fue estrecha. En un documento se puede leer que el presidente municipal de Pátzcuaro Pedro S. Talavera envió un oficio a Lázaro Cárdenas, donde manifestaba su agradecimiento con la empresa de Ferrocarriles Nacionales de México por las mejoras hechas en la Estación del tren en beneficio del turismo y donde dice haber saludado al ingeniero Antonio Madrazo durante la permanencia de éste en la ciudad y "patentizándole cumplidos agradecimientos". ${ }^{17}$

El presidente municipal José Ramos Chávez también tuvo relación cercana con Cárdenas. Durante el tercer mandato de Ramos como edil en 1935, se realizaron en Pátzcuaro importantes obras, como la construcción del mercado municipal y la construcción de la pila de Los Pescados. ${ }^{18} \mathrm{El}$ ayuntamiento, que cambiaba constantemente de representantes, tenía que coadyuvar y dar continuidad a las obras impulsadas en el municipio por la presidencia de la República. En sesión de cabildo solían ser temas a tratar los apoyos ofrecidos por el presidente Lázaro Cárdenas para el embellecimiento de la ciudad y por lo tanto el compromiso que tenía el ayuntamiento para cooperar y ejecutarlas; como lo fue la reformación del tramo de carretera de la estación de ferrocarril.

En los documentos revisados se pude dar cuenta que Cárdenas estaba al tanto de las renovaciones de la Estación del Ferrocarril como lo había hecho con otras obras en la ciudad. Además de la información que le enviaban Madrazo y los presidentes municipales en turno, continuamente visitaba la ciudad -en el "tren Olivo"- y los alrededores para revisar personalmente las obras materiales que estaba impulsando. En sus viajes aprovechaba para tomarse unos días de descanso en su Quinta Eréndira. Aunque este inmueble lo utilizaba también como oficina, pues personas de todos los estratos sociales lo visitaban para hacerle peticiones o mostrarle su aprecio, y en ocasiones desde su despacho atendía asuntos de relevancia nacional, por lo que su secretario personal Luis I. Rodríguez tenía que desplazarse desde México para que el presidente firmara

(1936, 29 de mayo). AGNM-LCR 514.63/9, fs. 21 y 21 bis. 17 Carta del ingeniero Antonio Madrazo a Luis I. Rodríguez (1936, 4 de septiembre). AGNM-LCR 514.63/9, f. 10. 18 El kiosco retirado fue donado al pueblo vecino de Tzurumútaro. 
documentos de importancia. Algunas veces llegaba acompañado de Secretarios de Gobierno, gobernadores, embajadores y distintos personajes. En más de una ocasión se dio tiempo para participar en alguna ceremonia cívica y recibir informe del presidente municipal sobre las obras materiales más recientes, por ejemplo, la inauguración del teatro Emperador. En noviembre de 1939 llegó a Pátzcuaro pocos días antes de inaugurar la carretera Guadalajara-Morelia-México, obra que permitió mayor afluencia de turismo a Morelia, Pátzcuaro, Tzintzuntzan y Ario de Rosales, como era el deseo del presidente y una de las prioridades en su gobierno.

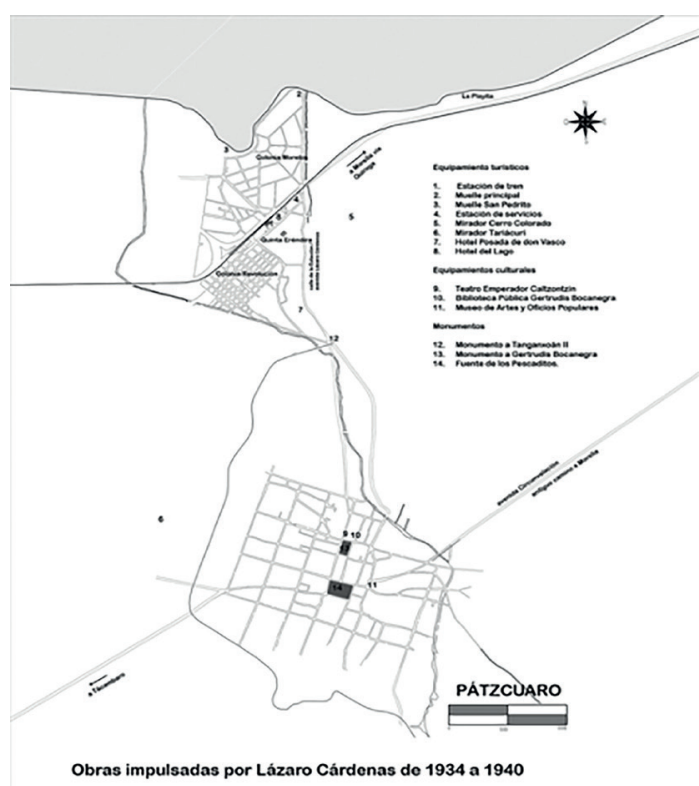

FIGURA 4. OBRAS IMPULSADAS POR LAZARO CARDENAS (1934-1940). FUENTE: ELABORACIÓN PROPIA.

\section{FUENTES DE CONSULTA}

Arteaga, A. (2010), Guillermo Ruiz y la Escuela Libre de Escultura y Talla Directa, conaculta, México.

Cárdenas, C. (2016), Cárdenas por Cárdenas, Grijalbo, México. Collingwood, R. G. (1994), The Idea of History, Oxford University Press, Oxford \& Nueva York.

Delpar, H. (1992), The Enormous Voque of Things Mexican Cultural Relations between the United States and Mexico, 19201935, The University of Alabama Press, Tuscaloosa \& London.

Ettinger, C. R. (2018a), "Roberto Cueva del Río en Michoacán. Arquitectura, pintura mural y la génesis de una iconografía regional (137-172)". En E. Mercado López (coord.). Arquitectura y murales en Michoacán. Génesis de una iconografía para la identidad regional, Fimax, Morelia.

Ettinger, C. R. (2018b), "Imaginarios pueblerinos. Las gasolineras del cardenismo en México", Registros, XII (2), pp. 28-50.

Ettinger, C. R. (2020a), "Arquitectura e imaginarios pueblerinos. La creación de equipamiento cultural y turístico para la región lacustre de Pátzcuaro Michoacán (1931-1942)”. En I. San Martín y A. Leal Menegus (coords.), Tránsitos e intervalos de lo privado a lo público, Dосомомо, México, pp. 67-83

Ettinger, C. R. (2020b), "Alberto Le Duc, Lázaro Cárdenas y una propuesta arquitectónica para Michoacán, México (1935-1945)”, Anales de Arte Americano e Investigaciones Estéticas, L (2), en prensa.

Fernández, J. (1936), Pátzcuaro, Secretaría de Hacienda y Crédito Público/Talleres de estampillas y valores, México.

García Sánchez, E. (2013), Pátzcuaro pintoresco, entre imaginarios y turismo (1920-1950). Tesis de Maestría en Arquitectura, Investigación y Restauración de Sitios y Monumentos. Facultad de Arquitectura/Universidad Michoacana de San Nicolás de Hidalgo.

García Sánchez, E. (2015), "El turismo en Pátzcuaro (México). Percepciones del visitante extranjero entre 1880-1920", Pasos, revista de turismo y patrimonio cultural, XIII (3), pp. 477-489.
García Sánchez, E. (2017), La arquitectura nacionalista del cardenismo. Las quintas campestres y el proyecto cultural en Michoacán (1927-1950). Tesis de Doctorado en Arquitectura, Facultad de Arquitectura, Universidad Michoacana de San Nicolás de Hidalgo.

Ginzberg, E. y Nowodworski, E. (1999), "Abriendo nuevos surcos: ideología, política y labor social de Lázaro Cárdenas en Michoacán, 1928-1932", Historia Mexicana, xLVII (3).

Goolsby, W. B. (ca. 1938), Guide to Mexico for the Motorist, The Pan American Press, Dallas.

Jackson, J. B. (2011), Las carreteras forman parte del paisaje, Gustavo Gili, Barcelona.

Jolly, J. (2018), Creating Pátzcuaro, Creating Mexico. Art, Tourism and Nation Building under Lázaro Cárdenas, University of Texas Press, Austin.

Martínez, J. M. (2016), Pátzcuaro, historias en el olvido, Genotipo Gráficos, Morelia.

Martínez, J. M. (2019), "Lázaro Cárdenas, impulsor del turismo y el arte en Pátzcuaro", Pasos, revista de Turismo y Patrimonio Cultural, XVII (5), pp. 1079-109.

Mercado López, E. (coord.) (2018), Arquitectura y murales en Michoacán. Génesis de una iconografía para la identidad regional, Fimax, Morelia.

Merrill, D. (2009), Negotiating Paradise. U.S. Tourism and Empire in Twentieth-Century Latin America, The University of North Carolina Press, Chapel Hill.

Power, T. S. (1940), Power's Guide to Mexico, Pan American Tourist Bureau, Laredo.

Rodríguez Prampolini, I. (1982), Juan O’Gorman. Arquitecto y Pintor, unam, México.

Sánchez Michel, V. (2013), De México para el Mundo. Centro de Enseñanza para Extranjeros. 90 años de enseñar la lengua y la cultura, UNAM, México.

Sosenski, G. (1999), La cuarta frontera de Baja California y el gobierno sudpeninsular de Francisco J. Múgica 1941-1945. Tesis de Maestría en Estudios Latinoamericanos, Universidad Nacional Autónoma de México, México. 